\title{
Mean platelet volume-to-lymphocyte ratio: a novel biomarker associated with overall survival in patients with nonmetastatic clear cell renal cell carcinoma treated with nephrectomy
}

\author{
Marcin Życzkowski ${ }^{1}$ Zbigniew Kaletka ${ }^{1} \cdot$ Pawel Rajwa $^{1}$ (1) - Grzegorz Rempega ${ }^{1} \cdot$ Paweł Stelmach $^{1} \cdot$ Rafał Bogacki $^{1}$. \\ Olga Łach-Wojnarowicz ${ }^{2}$. Ewa Paradysz ${ }^{1}$
}

Received: 19 October 2019 / Accepted: 7 January 2020 / Published online: 17 January 2020

(c) The Author(s) 2020

\begin{abstract}
Introduction Renal cell carcinoma is a highly aggressive malignancy that causes significant morbidity and mortality. The rising number of newly diagnosed renal tumors results in a great need to search for new preoperative markers to evaluate the course of the disease and to help select patients who would benefit the most from additional postoperative care. The aim of our study was to evaluate the prognostic value of mean platelet volume-to-lymphocyte ratio (MPVLR) in patients undergoing nephrectomy for nonmetastatic clear cell renal cell carcinoma (ccRCC).

Materials and methods A total number of 344 patients with proven nonmetastatic ccRCC treated with radical or partial nephrectomy at our institution between January 2003 and December 2012 were included in our analysis. Based on the optimal cut-off value of MPVLR, which was determined by the receiver operating characteristic curve, our study population was divided into two groups, with low and high MPVLR. Differences in overall survival between groups were compared using the Kaplan-Meier method with log-rank testing. The Cox proportional hazards regression model was applied to perform univariate and multivariate analysis.

Results Study subjects with high MPVLR were older and had more advanced tumors. Tumor necrosis and higher TNM stages were also more prevalent in this group of patients. Mortality in patients with high MPVLR was significantly higher than in patients with low MPVLR. In the multivariate analysis, after adjustment for pathological and clinical covariates, high $\operatorname{MPVLR}(\geq 3.61)$ was independently associated with higher long-term overall mortality in nonmetastatic ccRCC patients. Conclusion MPVLR is an easily obtainable prognostic marker for overall survival in nonmetastatic ccRCC patients treated with nephrectomy.
\end{abstract}

Keywords Renal cell cancer $\cdot$ Renal cell carcinoma $\cdot$ RCC $\cdot$ MPVLR $\cdot$ MPV

\section{Introduction}

Renal cell carcinoma (RCC) is a highly aggressive malignancy that is one of the most common malignancies worldwide $[1,2]$. It represents $2-3 \%$ of all cancers in global

Pawel Rajwa

pawelgrajwa@gmail.com

1 Department of Urology, School of Medicine With the Division of Dentistry in Zabrze, Medical University of Silesia in Katowice, 3 Maja Street 13-15, 41-800 Zabrze, Poland

2 Student Scientific Society, Department of Urology, Medical University of Silesia, 3 Maja Street 13-15, 41-800 Zabrze, Poland population [1]. Men are almost twice more likely to develop RCC than women, with peak incidence occurring between 60 and 70 years of age [1]. The most common risk factors are inter alia: cigarette smoking, obesity, hypertension and diabetes mellitus, which are considered as civilization diseases [1, 2]. Clear cell RCC (ccRCC), which is the main interest of our paper, is the most common histologic type of kidney cancer $[1,3]$. It is responsible for approximately $65-75 \%$ of RCC cases [3]. The first-line treatment for localized kidney cancer is surgical resection, either by partial or radical nephrectomy [1]. Nevertheless, approximately $10-50 \%$ of patients undergoing surgical treatment develop a disease recurrence after surgical treatment, which is associated with higher long-term mortality [4-6]. Nowadays, due to significant improvement in diagnostic radiology, we 
observe rising prevalence of incidental renal tumors $[2,7]$. Despite the fact that the 5-year overall survival (OS) for all types of RCC has increased in recent years, it still remains unacceptable [2]. In addition, the rising number of newly diagnosed small renal masses, especially in patients with many comorbidities, results in a great need to search for new preoperative markers to evaluate the course of the disease and to help select patients who would benefit the most from additional postoperative care $[1,8,9]$. One of the recently implemented complete blood count (CBC)-based indexes is mean platelet volume-to-lymphocyte ratio (MPVLR). It was first introduced in 2016 by Hudzik et al. as a potential prognostic marker in patients with diabetes mellitus and myocardial infarction [10]. Regarding the components of the MPVLR and the existing crosstalk between blood cells and cancer, we have assumed that MPVLR might have a prognostic value in surgically treated nonmetastatic ccRCC patients. Hereby, we present the first study which confirms the association between preoperative MPVLR and OS of M0 ccRCC patients undergoing partial or radical nephrectomy.

The first aim of our study was to evaluate the prognostic value of MPVLR in patients who underwent partial or radical nephrectomy for nonmetastatic ccRCC. The second goal was to analyze MPVLR in comparison with other clinical and pathological features.

\section{Materials and methods}

\section{Patients}

Medical records of 344 consecutive patients who underwent partial or radical nephrectomy for M0 clear cell renal cell carcinoma (ccRCC) at our institution between January 2003 and December 2012 were retrospectively analyzed. Histopathological, demographic and laboratory data, information on comorbidities and operative methods were retrieved from pathology reports from the Department of Pathology and from medical reports from the Department of Urology at our institution. Patients suffering from non-ccRCC tumor, distant metastases and those with confounding severe inflammatory and neoplastic processes were initially excluded from the study. Due to the change in tumor staging system during the observational period, TNM classification was assessed in compliance with the American Joint Committee on Cancer, 7 th edition (2010). Tumor grading was performed according to the Fuhrman system. Mean platelet volume (MPV) and lymphocyte count were obtained from preoperative complete blood counts which were performed median 3 (range 0-26) days prior to nephrectomy, and were available for all analyzed patients. Mean platelet volume-to-lymphocyte ratio (MPVLR) was calculated as MPV divided by lymphocyte count $\left(\times 10^{3} / \mathrm{mm}^{3}\right)$.

\section{Patient follow-up}

Information on survival was obtained from the Centre for Document Personalization of the Polish Ministry of Interior and Administration, which stores, among others, the exact date of death of every Polish citizen since the mid-1980s. Complete follow-up data were available for all analyzed patients. The primary study endpoint was OS, defined as time (months) from surgical intervention to all-cause death or the date of the end of follow-up, which was May 15, 2016.

\section{Statistical analysis}

Continuous variables are presented as median (interquartile range). Dichotomous variables are presented as percentages. Comparisons of baseline characteristics, laboratory and pathological findings were performed using the Mann-Whitney $U$ test and the Chi-squared test for continuous and categorical variables, respectively. Optimal cut-off value of MPVLR for overall mortality prediction was determined using receiver operating characteristic (ROC) curve analysis and the Youden method. Based on optimal cut-off value of MPVLR, study population was divided into two groups: high MPVLR group with MPVLR higher than or equal to the optimal cut-off value, and low MPVLR group with MPVLR lower than the optimal cut-off value. Differences in OS between groups were compared using the Kaplan-Meier method with log-rank testing. The Cox proportional hazards regression model was applied to perform univariate and multivariate analysis. Variables that had $p$ value lower than 0.05 in univariate analysis were entered into multivariate analysis. Statistical analyses were performed using the STATISTICA 12 software with Medical Bundle (StatSoft Inc., Tulsa, Oklahoma, USA).

\section{Results}

Median follow-up was 2184 (interquartile range 1553-3243) days. During the observation period, overall survival rate in the whole study population was $62.8 \%$. ROC curve for MPVLR in the prediction of overall mortality is depicted in Fig. 1. Optimal cut-off value of MPVLR for death prediction was 3.61. Comparison of baseline characteristics, laboratory and pathological findings between low and high MPVLR groups is presented in Table 1. Subjects with high MPVLR were older and had more pathologically advanced tumors. Tumor necrosis and higher TNM stages were also more prevalent in this group of patients. There were no differences between patients with high and low MPVLR in terms of sex, lymph node involvement, presence of sarcomatoid 


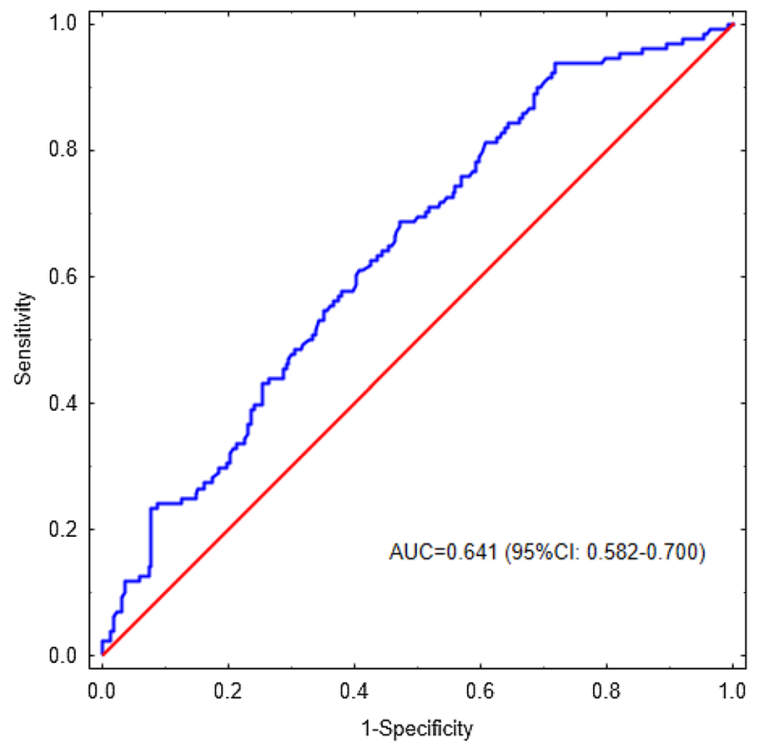

Fig. 1 Receiver operating characteristic (ROC) curve for MPVLR in the prediction of overall mortality in patients with nonmetastatic CCRCC undergoing nephrectomy. AUC area under the curve, $C I$ confidence interval, MPVLR mean platelet volume-to-lymphocyte ratio, $C C R C C$ clear cell renal cell carcinoma

feature, tumor grade and tumor size. Mortality in patients with high MPVLR was significantly higher than in ones with low MPVLR (Fig. 2). In multivariate analysis, after adjustment for clinicopathological covariates, high MPVLR $(\geq 3.61)$ was independently associated with greater longterm mortality in nonmetastatic ccRCC patients (Table 2).

\section{Discussion}

This study addressed the association of MPVLR with overall survival in study subjects with nonmetastatic ccRCC undergoing surgical treatment. Hereby, we present the first clinical study, which confirms a significant, prognostic relationship between high preoperative MPVLR and greater long-term mortality of cancer patients.

Up to now, numerous studies reported different prognostic factors affecting OS in RCC patients, but none of them emerged as a perfect indicator for prognosis $[1,11,12]$. The paradox lies in the fact that a new preoperative biomarker is needed to identify patients with highest long-term mortality, as such patients would benefit most from additional treatment; yet, the majority of currently reported predictors are based on pathologic examination of postoperative specimen, such as tumor grade and stage, cellular anaplasia and tumor histology [1]. The prognostic value of these models is considered to be insufficient and thus needs further improvements, which could be obtained with the addition of a preoperative biomarkers. However, it must be pointed out that the biggest drawbacks of most of the currently studied markers, such as hypoxia-inducible factor (HIF) or microRNAs (miRNAs,) are their high cost and low availability [13-15]. The solution might be found in cheap and easy obtainable blood-based indicators. Different complete blood count (CBC) parameters were reported to have an association with overall survival in RCC, such as neutrophil count, platelet count, neutrophil-to-lymphocyte ratio and mean platelet volume [16-21]. These markers are routinely used in everyday practice. Mean platelet volume-to-lymphocyte ratio (MPVLR) was reported to be associated with coronary collateral circulation development in patients with stable angina pectoris as well as with poor short- and long-term prognosis in patients with diabetes mellitus and acute myocardial infarction $[10,22]$. To our knowledge, this is the first study to investigate the association between MPVLR and overall survival in cancer patients.

MPVLR value, which is counted as MPV divided by lymphocyte count, represents the interplay between cancer and two different blood cells lines. Both, platelets and lymphocytes, take part in carcinogenesis and have separate developmental pathways, that are influenced by growing tumor. We hypothesize that elevated MPVLR might reflect a deteriorated interaction between tumor cells, blood platelets and lymphocyte-dependent immune response. A growing number of studies deliver evidence to support the potentially important role of platelets in the process of tumor cell growth and metastasis [23, 24]. There is strong evidence, that the actual feature that illustrates more precisely the function and activity of platelets is their size-MPV [25]. Larger platelets contain more dense granules and have a higher thrombogenocity potential [26]. Considering MPV prognostic value in RCC patients, Seles et al. retrospectively evaluated 652 patients with RCC and concluded that MPV is a significant predictor of recurrences and cancerspecific deaths [20]. Also, Yun et al. determined the association between lower mean platelet volume and prognosis in RCC, and reported that low MPV is a predictor of adverse clinical outcome [19]. On the other hand, decreased level of lymphocytes is strongly associated with the suppression of the immune system during carcinogenesis [27]. Saroha et al. retrospectively analyzed preoperative blood cell counts in 430 patients with ccRCC undergoing primary surgical treatment [27]. The study showed that lymphopenia was associated with lower overall survival regardless of tumor grade and stage, nuclear grade, patient's age, tobacco smoking and comorbidity index [27]. As described, the relationship between RCC and MPVLR remains complex, as MPVLR may reflect the aggressiveness of the tumor, altered platelet-mediated immunity and decreased lymphocyte-mediated immune response.

We acknowledge that the retrospective nature of our study and the fact that we were not able to obtain postoperative 
Table 1 Baseline characteristics, laboratory and pathological findings

\begin{tabular}{|c|c|c|c|c|}
\hline & \multirow{2}{*}{$\begin{array}{l}\text { Total } \\
n=344\end{array}$} & \multicolumn{3}{|l|}{ MPVLR } \\
\hline & & $\begin{array}{l}\text { Low }(<3.61) \\
n=69\end{array}$ & $\begin{array}{l}\operatorname{High}(\geq 3.61) \\
n=275\end{array}$ & $p$ value \\
\hline Sex & & & & 0.07 \\
\hline Male & $50.29 \%$ & $40.58 \%$ & $52.73 \%$ & \\
\hline Female & $49.71 \%$ & $59.42 \%$ & $47.27 \%$ & \\
\hline Age (years) & $63.0[54.0-70.0]$ & $56.0[52.0-64.0]$ & $65.0[56.0-71.0]$ & 0.00007 \\
\hline BMI $\left[\mathrm{kg} / \mathrm{m}^{2}\right]$ & 27.17 [24.57-30.67] & $28.87[24.85-32.05]$ & $27.1[24.51-30.17]$ & 0.19 \\
\hline Hemoglobin (g/dl) & $13.8[12.7-14.8]$ & $13.8[13.1-14.7]$ & $13.7[12.4-14.9]$ & 0.35 \\
\hline Red blood cell count $\left(10^{6} / \mathrm{mm}^{3}\right)$ & $4.54[4.28-4.87]$ & $4.64[4.38-4.92]$ & $4.51[4.26-4.87]$ & 0.13 \\
\hline White blood cell count $\left(10^{3} / \mathrm{mm}^{3}\right)$ & $6.7[5.6-8.2]$ & $8.4[6.6-9.1]$ & $6.35[5.5-7.69]$ & $<0.0001$ \\
\hline Lymphocytes $\left(10^{3} / \mathrm{mm}^{3}\right)$ & $1.9[1.5-2.4]$ & $2.7[2.4-3.2]$ & $1.8[1.5-2.1]$ & $<0.0001$ \\
\hline Neutrophils $\left(10^{3} / \mathrm{mm}^{3}\right)$ & $3.85[3.1-5.1]$ & $4.1[3.2-5.4]$ & $3.8[3.0-4.9]$ & 0.07 \\
\hline Monocytes $\left(10^{3} / \mathrm{mm}^{3}\right)$ & $0.4[0.32-0.6]$ & $0.5[0.4-0.6]$ & $0.4[0.3-0.54]$ & 0.06 \\
\hline Platelets $\left(10^{3} / \mathrm{mm}^{3}\right)$ & $238.0[194.0-297.0]$ & $276.0[231.0-321.0]$ & $230.0[187.0-287.0]$ & 0.0007 \\
\hline MPV (fl) & $9.4[8.3-10.8]$ & $8.3[7.5-9.3]$ & $9.75[8.4-11.0]$ & $<0.0001$ \\
\hline MPVLR & $4.95[3.79-6.27]$ & $3.21[2.72-3.38]$ & $5.43[4.5-6.58]$ & $<0.0001$ \\
\hline Sarcomatoid feature & & & & 0.85 \\
\hline Present & $1.83 \%$ & $1.54 \%$ & $1.90 \%$ & \\
\hline Absent & $98.17 \%$ & $98.46 \%$ & $98.10 \%$ & \\
\hline pT stage & & & & 0.01 \\
\hline pT1 & $64.97 \%$ & $80.00 \%$ & $61.34 \%$ & \\
\hline pT2 & $12.87 \%$ & $12.31 \%$ & $13.01 \%$ & \\
\hline pT3 & $21.56 \%$ & $7.69 \%$ & $24.91 \%$ & \\
\hline pT4 & $0.60 \%$ & $0.00 \%$ & $0.74 \%$ & \\
\hline Lymph node involvement & & & & 0.66 \\
\hline pNO & $96.51 \%$ & $95.38 \%$ & $96.73 \%$ & \\
\hline pN1 & $3.49 \%$ & $4.62 \%$ & $3.27 \%$ & \\
\hline TNM stage & & & & 0.05 \\
\hline I & $64.07 \%$ & $78.46 \%$ & $60.59 \%$ & \\
\hline II & $12.28 \%$ & $9.23 \%$ & $13.01 \%$ & \\
\hline III & $23.05 \%$ & $12.31 \%$ & $25.65 \%$ & \\
\hline IV & $0.60 \%$ & $0.00 \%$ & $0.74 \%$ & \\
\hline Tumor grade & & & & 0.23 \\
\hline G1 & $21.62 \%$ & $20.00 \%$ & $22.01 \%$ & \\
\hline $\mathrm{G} 2$ & $48.35 \%$ & $58.46 \%$ & $45.90 \%$ & \\
\hline G3 & $24.02 \%$ & $15.38 \%$ & $26.12 \%$ & \\
\hline G4 & $6.01 \%$ & $6.15 \%$ & $5.97 \%$ & \\
\hline Tumor size (mm) & $50.0[35.0-70.0]$ & $50.0[30.0-65.0]$ & $50.0[35.0-70.0]$ & 0.28 \\
\hline Nephrectomy & & & & 0.4 \\
\hline Partial & $33.43 \%$ & $37.68 \%$ & $32.36 \%$ & \\
\hline Radical & $66.57 \%$ & $62.32 \%$ & $67.64 \%$ & \\
\hline Tumor necrosis & & & & 0.01 \\
\hline Present & $14.51 \%$ & $4.62 \%$ & $17.06 \%$ & \\
\hline Absent & $85.49 \%$ & $95.38 \%$ & $82.94 \%$ & \\
\hline Overall survival & $62.79 \%$ & $88.41 \%$ & $56.36 \%$ & $0.00003^{\mathrm{a}}$ \\
\hline
\end{tabular}

Continuous variables are presented as median [interquartile range]. Dichotomous variables are presented as percentages CCRCC clear cell renal cell carcinoma, MPV mean platelet volume, MPVLR mean platelet volume-to-lymphocyte ratio ${ }^{\mathrm{a}} \log$-rank 


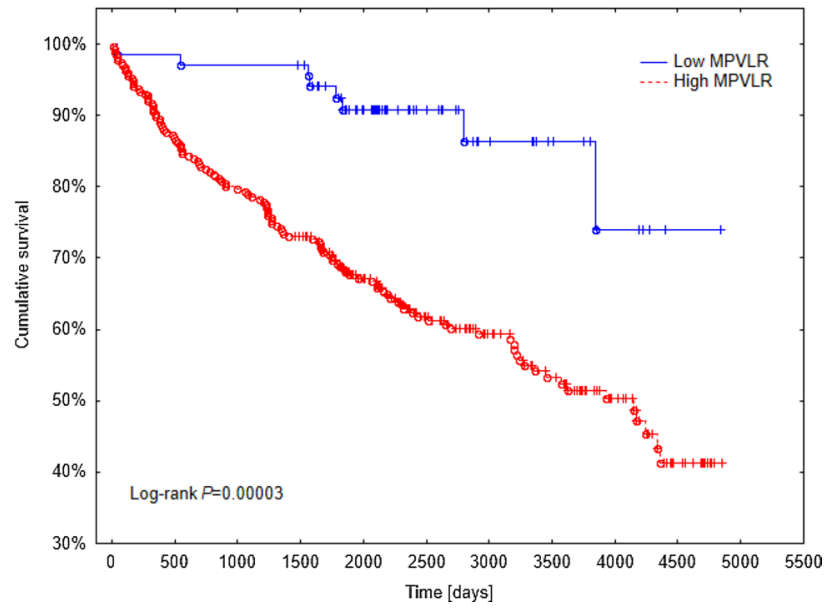

Fig. 2 The Kaplan-Meier curves for overall survival of ccRCC patients with high and low MPVLR therapy data and information on comorbidity burden of analyzed population, as well as relatively small sample size are major limitations of our research. Due to the fact that the RCC is most often diagnosed in elderly patients, further studies are needed to validate the prognostic value of MPVLR in younger cohorts. Due to aforementioned limitations, our finding should be considered as preliminary.

\section{Conclusions}

We have to report several key conclusions of our study. To our knowledge, this is the first study, which confirms the association between MPVLR and OS in patients with nonmetastatic ccRCC treated surgically. In our opinion, MPVLR may become a useful preoperative marker in everyday urological practice as it allows for a quick selection of patients with a higher risk of overall mortality in longterm observation. It must be also emphasized that MPVLR
Table 2 Predictors of overall mortality in patients with nonmetastatic CCRCC treated with nephrectomy - univariate and multivariate analysis

\begin{tabular}{|c|c|c|c|c|}
\hline & \multicolumn{2}{|c|}{ Univariate analysis } & \multicolumn{2}{|c|}{ Multivariate analysis } \\
\hline & HR (95\% CI) & $p$ value & HR (95\% CI) & $p$ value \\
\hline Sex & & 0.70 & & \\
\hline Female & Reference & & & \\
\hline Male & $1.07(0.76-1.51)$ & & & \\
\hline Age & & $<0.0001$ & & 0.0004 \\
\hline$<65$ years & Reference & & Reference & \\
\hline$\geq 65$ years & $2.43(1.69-3.47)$ & & $2.01(1.37-2.97)$ & \\
\hline pT stage & & $<0.0001$ & & $<0.0001$ \\
\hline $\mathrm{pT} 1+\mathrm{pT} 2$ & Reference & & Reference & \\
\hline $\mathrm{pT} 3+\mathrm{pT} 4$ & $4.33(3.04-6.17)$ & & $3.08(1.95-4.88)$ & \\
\hline Lymph node involvement & & 0.01 & & 0.74 \\
\hline pN0 & Reference & & Reference & \\
\hline $\mathrm{pN} 1$ & $2.41(1.22-4.74)$ & & $0.87(0.38-1.98)$ & \\
\hline Nephrectomy & & 0.003 & & 0.57 \\
\hline Radical & Reference & & Reference & \\
\hline Partial & $0.54(0.36-0.81)$ & & $1.15(0.71-1.86)$ & \\
\hline Sarcomatoid feature & & 0.03 & & 0.38 \\
\hline Absent & Reference & & Reference & \\
\hline Present & $3.09(1.14-8.39)$ & & $0.58(0.17-1.96)$ & \\
\hline Tumor necrosis & & $<0.0001$ & & 0.0002 \\
\hline Absent & Reference & & Reference & \\
\hline Present & $4.36(2.91-6.53)$ & & $2.45(1.53-3.91)$ & \\
\hline Grading & & $<0.0001$ & & 0.003 \\
\hline $\mathrm{G} 1+\mathrm{G} 2$ & Reference & & Reference & \\
\hline $\mathrm{G} 3+\mathrm{G} 4$ & $2.73(1.92-3.86)$ & & $1.92(1.24-2.95)$ & \\
\hline MPVLR & & 0.0001 & & 0.04 \\
\hline Low $(<3.61)$ & Reference & & Reference & \\
\hline $\operatorname{High}(\geq 3.61)$ & $4.01(1.96-8.21)$ & & $2.2(1.05-4.6)$ & \\
\hline
\end{tabular}

CCRCC clear cell renal cell carcinoma, $H R$ hazard ratio, $C I$ confidence interval, MPVLR mean platelet volume to lymphocyte ratio 
was significantly associated with TNM staging components and tumor necrosis, which may also be a valuable diagnostic marker in preoperative cancer assessment. To sum up, thanks to this simple, cheap and easily obtainable marker, there may be a chance to distinct patients requiring special postoperative care and to implement a more intensive treatment. Making key decision concerning the course of treatment can, through the use of MPVLR, proceed faster, more efficiently and with greater benefit for the patient. Nonetheless, further studies are necessary to validate the prognostic value of MPVLR in patients with ccRCC treated with nephrectomy.

\section{Compliance with ethical standards}

Conflict of interest The authors declare that they have no conflict of interest.

Open Access This article is licensed under a Creative Commons Attribution 4.0 International License, which permits use, sharing, adaptation, distribution and reproduction in any medium or format, as long as you give appropriate credit to the original author(s) and the source, provide a link to the Creative Commons licence, and indicate if changes were made. The images or other third party material in this article are included in the article's Creative Commons licence, unless indicated otherwise in a credit line to the material. If material is not included in the article's Creative Commons licence and your intended use is not permitted by statutory regulation or exceeds the permitted use, you will need to obtain permission directly from the copyright holder. To view a copy of this licence, visit http://creativecommons.org/licenses/by/4.0/.

\section{References}

1. Ljungberg B, Bensalah K, Canfield S, Dabestani S, Hofmann F, Hora $\mathrm{M}$ et al (2015) EAU guidelines on renal cell carcinoma: 2014 update. Eur Urol (Switzerland) 67:913-924. https://doi. org/10.1016/j.eururo.2015.01.005

2. Chow W-H, Dong LM, Devesa SS (2010) Epidemiology and risk factors for kidney cancer. Nat Rev Urol. https://doi.org/10.1038/ nrurol.2010.46

3. Inamura K (2017) Renal cell tumors: understanding their molecular pathological epidemiology and the 2016 WHO Classification. Int J Mol Sci (MDPI) 18:2195. https://doi.org/10.3390/ijms1 8102195

4. Yaycioglu O, Eskicorapci S, Karabulut E, Soyupak B, Gogus C, Divrik T et al (2013) A preoperative prognostic model predicting recurrence-free survival for patients with kidney cancer. Jpn J Clin Oncol (England) 43:63-68. https://doi.org/10.1093/jjco/hys 192

5. Eggener SE, Yossepowitch O, Pettus JA, Snyder ME, Motzer RJ, Russo P (2006) Renal cell carcinoma recurrence after nephrectomy for localized disease: predicting survival from time of recurrence. J Clin Oncol (United States) 24:3101-3106. https://doi. org/10.1200/JCO.2005.04.8280

6. Zisman A, Pantuck AJ, Wieder J, Chao DH, Dorey F, Said JW et al (2002) Risk group assessment and clinical outcome algorithm to predict the natural history of patients with surgically resected renal cell carcinoma. J Clin Oncol (United States) 20:4559-4566. https://doi.org/10.1200/JCO.2002.05.111
7. Ljungberg B, Campbell SC, Cho HY, Jacqmin D, Lee JE, Weikert $S$ et al (2017) The epidemiology of renal cell carcinoma. Eur Urol 60:615-621. https://doi.org/10.1016/j.eururo.2011.06.049

8. Bindayi A, Hamilton ZA, McDonald ML, Yim K, Millard F, McKay RR et al (2017) Neoadjuvant therapy for localized and locally advanced renal cell carcinoma. Urol Oncol Semin Orig Investig. https://doi.org/10.1016/j.urolonc.2017.07.015

9. Rajwa P, Życzkowski M, Paradysz A, Slabon-Turska M, Suliga K, Bujak K et al (2017) Novel hematological biomarkers predict survival in renal cell carcinoma patients treated with nephrectomy. Arch Med Sci. https://doi.org/10.5114/aoms.2017.70250

10. Hudzik B, Szkodzinski J, Lekston A, Gierlotka M, Polonski L, Gasior M (2016) Mean platelet volume-to-lymphocyte ratio: a novel marker of poor short- and long-term prognosis in patients with diabetes mellitus and acute myocardial infarction. J Diabetes Complicat (United States) 30:1097-1102. https://doi. org/10.1016/j.jdiacomp.2016.04.010

11. Grimes N, Tyson M, Hannan C, Mulholland C (2017) A systematic review of the prognostic role of hematologic scoring systems in patients with renal cell carcinoma undergoing nephrectomy with curative intent. Clin Genitourin Cancer 14:271-276. https://doi.org/10.1016/j.clgc.2016.01.006

12. Viers BR, Houston Thompson R, Boorjian SA, Lohse CM, Leibovich BC, Tollefson MK (2014) Preoperative neutrophillymphocyte ratio predicts death among patients with localized clear cell renal carcinoma undergoing nephrectomy. Urol Oncol (United States) 32:1277-1284. https://doi.org/10.1016/j.urolo nc. 2014.05.014

13. Fan Y, Li H, Ma X, Gao Y, Chen L, Li X et al (2015) Prognostic significance of hypoxia-inducible factor expression in renal cell carcinoma: a PRISMA-compliant systematic review and metaanalysis. Medicine (Baltimore, United States) 94:e1646. https ://doi.org/10.1097/MD.0000000000001646

14. Stahlhut C, Slack FJ (2013) MicroRNAs and the cancer phenotype: profiling, signatures and clinical implications. Genome Med Biomed Cent 5:111. https://doi.org/10.1186/gm516

15. Gowrishankar B, Ibragimova I, Zhou Y, Slifker MJ, Devarajan $\mathrm{K}$, Al-Saleem T et al (2014) MicroRNA expression signatures of stage, grade, and progression in clear cell RCC. Cancer Biol Ther (United States) 15:329-341. https://doi.org/10.4161/ cbt. 27314

16. Fox P, Hudson M, Brown C, Lord S, Gebski V, De Souza P et al (2013) Markers of systemic inflammation predict survival in patients with advanced renal cell cancer. Br J Cancer 109:147153. https://doi.org/10.1038/bjc. 2013.300

17. Gu L, Li H, Gao Y, Ma X, Chen L, Li X et al (2015) The association of platelet count with clinicopathological significance and prognosis in renal cell carcinoma: a systematic review and meta-analysis. PLoS One (United States) 10:e0125538. https:// doi.org/10.1371/journal.pone.0125538

18. Życzkowski M, Rajwa P, Gabrys E, Jakubowska K, Jantos E, Paradysz A (2017) The relationship between red cell distribution width and cancer-specific survival in patients with renal cell carcinoma treated with partial and radical nephrectomy. Clin Genitourin Cancer. https://doi.org/10.1016/j.clgc.2017.12.003

19. Yun Z-Y, Zhang X, Liu Y-S, Liu T, Liu Z-P, Wang R-T et al (2017) Lower mean platelet volume predicts poor prognosis in renal cell carcinoma. Sci Rep 7:6700. https://doi.org/10.1038/s41598-01707168-X

20. Seles M, Posch F, Pichler GP, Gary T, Pummer K, Zigeuner R et al (2017) Blood platelet volume represents a novel prognostic factor in patients with nonmetastatic renal cell carcinoma and improves the predictive ability of established prognostic scores. J Urol (United States) 198:1247-1252. https://doi.org/10.1016/j. juro.2017.07.036 
21. Prokopowicz G, Zyczkowski M, Nowakowski K, Bogacki R, Bryniarski P, Paradysz A (2016) Basic parameters of blood count as prognostic factors for renal cell carcinoma. Biomed Res Int (United States) 2016:8687575. https://doi. org/10.1155/2016/8687575

22. Ornek E, Kurtul A (2017) Relationship of mean platelet volume to lymphocyte ratio and coronary collateral circulation in patients with stable angina pectoris. Coron Artery Dis (England) 28:492497. https://doi.org/10.1097/MCA.0000000000000530

23. Tesfamariam B (2016) Involvement of platelets in tumor cell metastasis. Pharmacol Ther (England) 157:112-119. https://doi. org/10.1016/j.pharmthera.2015.11.005

24. Riedl J, Pabinger I, Ay C (2014) Platelets in cancer and thrombosis. Hamostaseologie (Germany) 34:54-62. https://doi. org/10.5482/HAMO-13-10-0054

25. Martin JF, Shaw T, Heggie J, Penington DG (1983) Measurement of the density of human platelets and its relationship to volume. Br J Haematol (England) 54:337-352
26. Wasilewski J, Desperak P, Hawranek M, Cislak A, Osadnik T, Pyka L et al (2016) Prognostic implications of mean platelet volume on short- and long-term outcomes among patients with non-ST-segment elevation myocardial infarction treated with percutaneous coronary intervention: a single-center large observational study. Platelets (England) 27:452-458. https://doi. org/10.3109/09537104.2016.1143919

27. Saroha S, Uzzo RG, Plimack ER, Ruth K, Al-Saleem T (2013) Lymphopenia is an independent predictor of inferior outcome in clear cell renal carcinoma. J Urol (United States) 189:454-461. https://doi.org/10.1016/j.juro.2012.09.166

Publisher's Note Springer Nature remains neutral with regard to jurisdictional claims in published maps and institutional affiliations. 